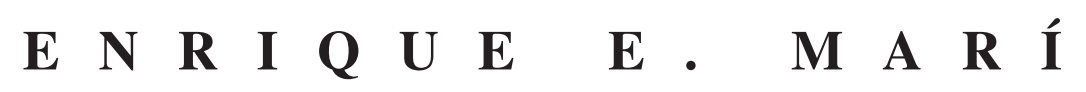




\title{
ENRIQUE MARÍ (1928-2001)
}

\author{
Christian Courtis \\ Universidad de Buenos Aires
}

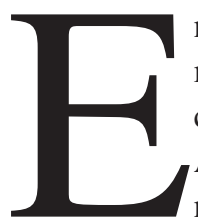

nrique Marí falleció hace algunos meses, un día gris y frío del mes de julio. La noticia fue un gran golpe para mí, y para muchos otros compañeros que aprendimos y enseñamos con él. Aunque los medios de comunicación publicaron varios homenajes, sentí una gran desazón al notar que, entre las alusiones a la figura y al trabajo de Enrique, pocas voces reivindicaron su obra jurídica. Estas breves y apresuradas líneas están dedicadas a resaltar el valor de la obra de Marí en el campo del derecho, y a subrayar la intensa continuidad entre esa obra, el resto de sus preocupaciones teóricas y filosóficas y los valores que encarnó como profesor, como amigo y como persona.

Además de ejercer la profesión de abogado durante muchos años -se jubiló como abogado del Banco Central-, Enrique se dedicó en el plano académico a trasladar al campo de la teoría jurídica la amplitud de sus preocupaciones filosóficas, culturales y políticas. La magnitud de esta tarea sólo puede medirse a partir de las carencias y de la abierta hostilidad de la tradición teórica que campeaba y aún campea en las facultades de derecho, para hacerse cargo de problemas tales como las relaciones entre poder y derecho, derecho e ideología, saber y poder. Enrique asumió esta tarea -de ribetes que recuerdan al castigo de Sísifo- con pasión, humor y resignación, consciente de la abierta resistencia del medio a abrirse a otras ideas y disciplinas y a abandonar la tozuda contemplación del propio ombligo.

¿Cuáles son los hilos que vertebran los trabajos de Marí en el campo del derecho? Creo que su obra encarna los valores propios de su ethos vital: la enorme libertad de espíritu, la vocación crítica inclaudicable, la apertura interdisciplinaria poco común, la erudición gozosa, poética, guiada por el placer de la lectura y del debate de ideas, y el refrescante carácter libertario y antiautoritario que caracterizaba a sus ideales y a su trato con las personas. 
Si fuera posible hablar de un núcleo de sus preocupaciones teóricas en el terreno jurídico, creo que se trata de su interés por desnudar las determinaciones económicas y políticas del proyecto y de las categorías jurídicas de la modernidad, y su persistencia hasta nuestros días. El rasgo distintivo de su pluma es, sin embargo, la variedad y riqueza del material al que acude para ilustrar sus tesis: las conexiones entre teoría jurídica y concepciones científico-filosóficas reinantes, la economía política, la historia, las comparaciones culturales, la literatura. Se trata, creo, de una de las claves para entender la difícil ubicación de su obra en el panorama seco, casi desértico, de la producción jusfilosófica local, y el mayor interés despertado por sus aportes en el terreno de la filosofía y de las ciencias sociales.

Enrique dedicó gran parte de su vida a abrir puertas, a iniciar exploraciones, a proponer nuevos prismas de lectura. Basta con repasar algunos de sus aportes iniciáticos en el terreno de la teoría del derecho. Debemos a Enrique y a su amigo Jorge Lucio Rébori -secuestrado durante la dictadura militar y aún desaparecido- las primeras articulaciones de una epistemología jurídica de corte materialista en la Facultad de Derecho de la Universidad de Buenos Aires. Marí fue uno de los iniciadores de la teoría crítica del derecho en la Argentina, el introductor de los análisis de Michel Foucault, Gaston Bachelard, Louis Althusser y Nicos Poulantzas en el terreno jurídico, y un precursor en el enlace interdisciplinario de derecho y psicoanálisis.

Lejos de cualquier dogmatismo o encorsetamiento teórico, su obra propone lecturas del derecho que abrevan en aportes de la epistemología, la filosofía y la teoría social de los últimos treinta años. En esta línea, y en lo que tal vez constituya el puente más fecundo entre su obra filosófica y su obra jurídica, acercó a un campo dominado por la teoría jurídica de corte positivista y logicista la crítica epistemológica desarrollada durante gran parte del siglo XX al positivismo y el empirismo en las ciencias naturales, revelando la persistencia en el ámbito del derecho de criterios de demarcación de la cientificidad completamente superados en otras disciplinas científicas. Cabe, así, observar la continuidad de sus planteos en el campo de la epistemología de las ciencias -entre los que sobresalen Neopositivismo e ideología ${ }^{1}$ y Elementos de epistemología comparada ${ }^{2}$ - y sus trabajos dedicados a resaltar la influencia del neopositivismo lógico sobre el pensamiento jurídico. ${ }^{3}$ En el mismo sentido, proyectó sobre la teoría jurídica la discu-

\footnotetext{
${ }^{1}$ Marí, E. E., Neopositivismo e ideología, EUDEBA, Buenos Aires, 1974.

2 Marí, E. E., Elementos de epistemología comparada, Puntosur, Buenos Aires, 1990.

3 V., por ejemplo, su trabajo «Causalidad y teleología: intersección del pensamiento de Hans Kelsen con el positivismo lógico y la teleología de Rudolf Ihering. Un ejercicio de epistemología comparada», en Marí, E. E. y otros, Materiales para una teoría crítica del derecho, Abeledo Perrot, Buenos Aires, 1991, pp. 337-415.
} 
sión sobre el carácter ideológico de todo discurso científico ${ }^{4}$-aun de aquel que predica asepsia ideológica- y sobre la responsabilidad ética del jurista por sus decisiones de supuesto carácter tecnológico, ${ }^{5}$ haciéndose eco de los debates generados en el contexto de las ciencias naturales acerca de la responsabilidad del científico por el destino militar o industrial destructivo de sus invenciones. Una de las preocupaciones centrales de las investigaciones de Marí es el papel legitimador del derecho, y su articulación de un discurso racional autocalificado de científico con dispositivos destinados a provocar efectos disciplinadores en el imaginario social. La discusión epistemológica ilumina los aspectos opacos de esta relación: los lugares no nombrados de los que depende la supuesta racionalidad del discurso, y la mutua remisión del discurso legitimador y los dispositivos de empleo de la violencia jurídica. Para ello, Marí se apoya en el debate filosófico que se pregunta por las relaciones entre verdad, saber y poder, cuestionando las formulaciones epistemológicas que desvinculan a la ciencia de cualquier correlato externo.

Gran parte de este trabajo de develamiento ideológico adopta como blanco de crítica al modelo teórico dominante durante gran parte del siglo XX en la teoría jurídica, es decir, el positivismo. La propuesta teórica de Marí eligió explícitamente la estrategia de trabajar sobre las brechas, sobre los intersticios, sobre los resquicios abiertos por la teoría positivista ${ }^{6}$-a partir, en muchos casos, de la propia conciencia e incomodidad de esas fallas expresada por juristas paradigmáticos del positivismo, como Hans Kelsen-.

\footnotetext{
${ }^{4}$ V., por ejemplo, el papel que asigna al discurso de la dogmática jurídica en «Racionalidad e imaginario social en el discurso del orden», en Doxa. Cuadernos de Filosofía del Derecho, Nro. 3, Alicante, 1986, pp. 93-112, y en Marí, E. E. y otros, Derecho y psicoanálisis, Hachette, Buenos Aires, 1987, pp. 57-77; en sentido similar, «Las ficciones de legitimación en el derecho y la política: de la sociedad medieval a la sociedad contractual», en Marí, E. E., Papeles de Filosofía II, Biblos, Buenos Aires, 1996, pp. 291-318. Para una lectura en esa clave de la teoría de la exegética de la interpretación, v. «La interpetación de la ley. Análisis histórico de la Escuela Exegética y su nexo con el proceso codificatorio de la modernidad», Marí, E. E. y otros, en Materiales para una teoría crítica del derecho, cit., pp. 233-294.

${ }^{5}$ V., por ejemplo, «El castigo en el plano teórico», capítulo II de La problemática del castigo, Hachette, Buenos Aires, 1983, pp. 66-128, en especial su discusión de la justificación del castigo en el análisis económico del derecho de la Escuela de Chicago, pp. 116-128. En el mismo sentido, «Ciencia y Etica: el modelo de la ciencia martillo», en Doxa. Cuadernos de Filosofía del Derecho, Nro. 10, Alicante, 1991, pp. 319-327

${ }^{6}$ En sus propias palabras, jugando con el título de la Teoría Pura kelseniana, sobre las «impurezas de la teoría». Cfr. la respuesta dada por Enrique a una encuesta sobre tendencias de la filosofía del derecho en el mundo, organizada por la revista Doxa. V. Marí, E. E., «Problemas abiertos de la filosofía del derecho», en Doxa. Cuadernos de Filosofía del Derecho, Nro. 1, Alicante, 1984, pp. 159-167; en sentido similar, «¿Qué iusfilosofía para la Argentina de la posmodernidad?», en Revista No Hay Derecho, Nro. 3, Buenos Aires, 1990. Se trata de los pocos trabajos en los que Marí ofrece una síntesis de sus preocupaciones teóricas en el plano de la filosofía del derecho.
} 
Esta elección, relacionada con su abierta renuencia a la fundación de una nueva metanarrativa o «gran teoría», tiene como correlato una aparente dispersión de la obra de Enrique, cuya unidad parece quedar supeditada al hilván inteligente del lector. No hay manual, instrucciones de uso o marco de interpretación predeterminado que reúna sus trabajos de acuerdo a un plan: no es difícil, sin embargo, vincular esta configuración con la abierta defensa de un modelo epistemológico flexible, en el que, más que por la definición a priori de un método riguroso, el valor de un trabajo teórico se estime a partir de la luz que echen sus resultados. Cabe destacar, además, el papel que juegan en tal modelo abierto el placer, la orientación subjetiva, la creatividad, la libertad de fuentes y de metas elegidas por el propio investigador. Por no estar atada a mandatos epistemológicos rígidos, la obra de Enrique es a la vez un llamado a -y un ejemplo de- la ruptura de campos categoriales rígidamente demarcados, al diálogo entre disciplinas.

Ciertamente, la contribución con la que más se lo vincula es la introducción de Michel Foucault en el campo del derecho -a fines de la década del 70, mucho antes de la difusión de la obra del filósofo francés en los círculos de las ciencias sociales-. En esta línea, se destacan su libro dedicado al discurso de Bentham sobre el castigo, y a su relectura por Foucault, ${ }^{7}$ y su señero trabajo de proyección de la investigación foucaultiana del caso Pierre Rivière sobre la construcción del discurso jurídico. ${ }^{8}$ Marí toma como ejemplo la historia del expediente para ilustrar las discontinuidades de la producción de una pieza del discurso jurídico -en el caso, la sentencia judicial, aunque el autor señala expresamente la posibilidad de repetir el ejercicio con otros ejemplos, como la sanción de normas-. Impugnando los intentos de reconstrucción del discurso del derecho en términos silogísticos, el trabajo postula que el espacio del proceso judicial es un campo de batalla por la imposición de sentidos, determinado externamente por debates aparentemente ajenos a la discusión técnica de los juristas. El discurso del derecho es significativo por lo que dice, pero también por lo que oculta. Esta concepción invita a rechazar las explicaciones autorreferentes acerca del fenómeno jurídico, y a investigar las conexiones que vinculan al derecho -en tanto lugar estratégico de producción de sentido y de legitimación- con otros sucesos económicos, políticos y sociales.

\footnotetext{
${ }^{7}$ Marí, E. E., La problemática del castigo, cit.

8 «'Moi, Pierre Rivière...' y el mito de la uniformidad semántica en las ciencias sociales y jurídicas», en Marí, E. E. y otros, El discurso jurídico. Perspectiva psicoanalítica y otros abordajes epistemológicos, Buenos Aires, Hachette, 1982. La reflexión es retomada en Marí, E. E. «El retorno del caso Rivière. Un debate postergado. Veinte años después», en Doxa, Cuadernos de Filosofía del Derecho, Nro. 15-16, T. II, Alicante, 1994, pp. 883-896, y en Papeles de Filosofía II, cit.
} 
En un plano igualmente relevante y original se encuentra la contribución de Enrique a la vinculaciones entre derecho y psicoanálisis. Sus textos, y su labor de difusión de autores como Pierre Legendre, constituyen un aporte inédito en nuestro país, que ilumina la correlación de los planteos de la teoría psicoanalítica con las funciones sociales cumplidas por el derecho. ${ }^{9}$ Marí interpela al derecho a partir de elementos de la teoría freudiana y lacaniana, señalando agudamente estructuras comunes: el papel de las ficciones y los mitos fundacionales, el lugar simbólico de la autoridad, el estatuto organizador de la filiación, las vinculaciones entre amor y poder, la representación del poder en el cuerpo.

Particular atención merece el interés de Marí por la obra menos difundida de Hans Kelsen. Y es que, de acuerdo a la propia justificación de Enrique, Kelsen era demasiado curioso e inteligente como para circunscribir su producción a la receta metodológica que él mismo propugnaba. Prueba de ello es una extendida serie de trabajos en los que Kelsen se aparta de los estrechos márgenes trazados por su propia teoría, y tematiza el derecho a través del material proporcionado por otros campos disciplinarios: el psicoanálisis, los estudios antropológicos, la teología, la teoría de las ficciones. Marí es un meticuloso seguidor de las huellas de este «otro Kelsen», y se ha dedicado a mostrar un costado fascinante del jurista austríaco que la teoría dominante había silenciado. ${ }^{10}$

Otro de los ejes de su obra está constituido por su trabajo sobre la teoría de las ficciones, y el papel que ellas ocupan en la construcción del discurso del derecho. ${ }^{11}$ Esta preocupación conecta la teorización sobre las ficciones en la filosofía, la literatura y el derecho, conexión aprovechada por

\footnotetext{
${ }^{9}$ V., por ejemplo, «Una lectura freudiana de Hans Kelsen», en Marí, E. E. y otros, Materiales para una teoría crítica del derecho, cit., pp. 13-26, «Diferentes modos de acceso a la articulación entre derecho y psicoanálisis», en Courtis, C. (comp.), Desde otra mirada. Textos de teoría crítica del derecho, EUDEBA, Buenos Aires, 2001, pp. 39-57, y el empleo de Lacan en «La teoría de las ficciones en Jeremy Bentham», en Marí, E. E. y otros, Derecho y psicoanálisis, cit., pp. 46-54.

${ }^{10}$ V., por ejemplo, «Una lectura freudiana de Hans Kelsen», cit., y «Hans Kelsen. La doctrina del eros platónico como un tratado freudiano de sexualidad», en Marí, E. E. y otros, Materiales para una teoría crítica del derecho, cit., pp. 27-71, respectivamente; «Racionalidad e imaginario social en el discurso del orden», cit., 72-77. Marí es responsable además de la publicación y de la revisión técnica de «La función de la Constitución», artículo de 1964 en el que Kelsen, después de una larga serie de marchas y contramarchas teóricas, califica a su «norma fundamental» de «ficción». V. Kelsen, H., «La función de la Constitución», en Marí, E. E. y otros, Derecho y psicoanálisis, cit., pp. 79-88. En la misma vena, tradujo «El alma y el derecho», texto de Kelsen de 1936 incluido en Materiales para una teoría crítica del derecho, cit., pp. 117-148.

${ }^{11}$ V., por ejemplo, «La teoría de las ficciones en Jeremy Bentham», cit.; «Las ficciones de legitimación en el derecho y la política: de la sociedad medieval a la sociedad contractual», cit.
} 
Marí para enriquecer sus textos jurídicos con ejemplos literarios. En los últimos años, y en conexión con su constante interés por las ficciones, Enrique se dedicó a las relaciones entre derecho y literatura. ${ }^{12}$ Su textos más recientes son un ejemplo de frescura y apertura mental: en ellos convive el diálogo con autores de las más variadas corrientes teóricas -desde Gadamer hasta Richard Posner-, y una desprejuiciada revisión de la literatura universal de todas las épocas.

El trabajo de Enrique tampoco estuvo ausente del campo del derecho penal. Varios de sus trabajos ya citados abordan explícitamente el tratamiento filosófico y literario del castigo ${ }^{13}$; en otro registro, su trabajo sobre la teoría de la ideología ha abierto novedosas posibilidades de lectura de la noción de control social ${ }^{14}$. Igualmente interesante para el derecho penal ha resultado su investigación sobre el componente jurídico del movimiento positivista argentino, ${ }^{15}$ dadas las indudables influencias de esa postura científico-filosófica sobre el diseño de normas, instituciones y dispositivos de control penal en nuestro país. Enrique fue miembro del comité consultivo de Poder y Control, de Delito y Sociedad y de Nueva Doctrina Penal, y participante de numerosos congresos y eventos de esta disciplina.

Aunque tributario del marxismo estructuralista, la obra de Marí se aleja de todo canon ortodoxo. Los rasgos de una filosofía inexorable de la historia tienen apenas lugar en sus escritos, en los que sí resalta el compromiso crítico y la intepretación de corte materialista. Sin embargo, la variedad del material teórico al que acude y la adopción de un punto de vista microfísico para analizar relaciones de poder aportan a su enfoque un estilo que lo distancia de cualquier convencionalismo. Heterodoxo, iconoclasta, inclasificable, no es extraño que haya sido ignorado y aun víctima de maccartismo, desplazamientos y persecución en el ámbito de la Facultad de Derecho, no sólo en épocas de dictadura, sino también durante la recuperación democrática. Su respuesta ante los contratiempos siempre fue la misma: paciente, éticamente íntegra, lejana a cualquier componenda y transacción po-

${ }^{12}$ V. «Robert Musil y la crisis del Reino de Kakania», en Marí, E. E., Papeles de Filosofía II, cit., pp. 65-89; «Derecho y Literatura. Algo de lo que sí se puede hablar pero en voz baja», en Doxa, Cuadernos de Filosofía del Derecho, Nro 21, T. II, Alicante, 1998, pp. 251-287.

${ }^{13}$ V. Marí, E. E., La problemática del castigo, cit.

${ }^{14}$ Cfr. «Igualdad y seguridad: el objeto del control», en R. Bergalli y E. E. Marí (coords.), Historia ideológica del control social (España-Argentina, siglos XIX y XX), PPU, Barcelona, 1989, y los trabajos allí reunidos bajo esta perspectiva.

15 «El marco jurídico del movimiento positivista argentino», en Biagini, H. (comp.), El movimiento positivista argentino, Ed. de Belgrano, Buenos Aires, 1985, reimpreso en Papeles de Filosofía II, cit., pp. 141-204; Marí, E. E., «José Ingenieros: el alienista, si loco y el delito», en Revista Todo es Historia, 173, Buenos Aires , 1981, reimpreso en Marí, E. E., Papeles de filosofía, Ed. Biblos, Buenos Aires, 1993, pp. 185-194. 
lítica, firme en la defensa de sus ideas y coloreada por un envidiable sentido del humor y de la ironía. Fruto, tal vez, de años de tener razón en minoría, de articular respuestas lúcidas desde la oposición.

Es lamentable que ni a Enrique ni a su obra se les haya dado el lugar que merecen en el ámbito del derecho. A quienes compartimos su enseñanza y el placer de ayudarlo, nos será difícil acostumbrarnos a su ausencia. A quienes no llegaron a conocerlo, les queda el tardío consuelo de revisar sus escritos. 
$\triangle \quad$ DOXA 24 (2001) 